\title{
Optimising HPV vaccination communication to adolescents: a discrete choice experiment
}

Authors:

Sandra Chyderiotis 1

Jonathan Sicsic 2

Jocelyn Raude 3, 4

Isabelle Bonmarin 5

Florian Jeanleboeuf 6, 7

Anne-Sophie Le Duc Banaszuk 8

Aurélie Gauchet 9

Sébastien Bruel 10, 11

Morgane Michel 12, 13, 14

Bruno Giraudeau 15

Nathalie Thilly 16, 17

Judith E. Mueller 1, 3

1 Unité de Recherche et d'Expertise Epidémiologie des maladies émergentes, Institut Pasteur, 25 rue du Dr Roux - 75724 Paris cedex 15, France

2 LIRAES (EA 4470), University of Paris, Paris, France.

3 EHESP French School of Public Health, Rennes, Paris, France 
4 Unité des Virus Emergents (UVE: Aix-Marseille Univ - IRD 190 - Inserm 1207 - IHU

Méditerranée Infection), Marseille, France

5 Santé publique France, Saint-Maurice, France

6 GIMAP : groupe Immunité des Muqueuses et Agents Pathogènes, EA 3064, Université Jean Monnet, Université de Lyon, Saint-Etienne, France

7 Chaire PREVacCI Prévention, Vaccination et Contrôle de l'Infection, Institut PRESAGE, Université Jean Monnet, Université de Lyon, Saint-Etienne, France

8 Centre Régional de Coordination des Dépistages des cancers-Pays de la Loire, Angers, France

9 Université Grenoble Alpes, LIP/PC2S, EA 4145, Grenoble, France

10 HESPER EA7425, Saint-Etienne-Lyon University, Saint-Etienne, France

11 CIC-INSERM 1408, University Hospital of Saint-Etienne, Saint-Etienne, France

12 Université de Paris, ECEVE, Paris, France

13 Assistance Publique-Hôpitaux de Paris, Hôtel Dieu, URC Eco Ile-de-France / Hôpital Robert Debré, Unité d'épidémiologie clinique, Paris, France

14 INSERM, ECEVE UMR 1123, Paris, France

15 Université de Tours, Université de Nantes, INSERM, SPHERE U1246, Tours, France ;

INSERM CIC 1415, CHRU de Tours, Tours, France

16 Université de Lorraine, APEMAC, Nancy, France

17 Université de Lorraine, CHRU-Nancy, Département Méthodologie, Promotion, Investigation, Nancy, France 


\begin{abstract}
Background: Human Papillomavirus (HPV) vaccine coverage in France is below 30\%, despite proven effectiveness against HPV infections and (pre-)cancerous cervical lesions. To optimise vaccine promotion among adolescents, we used a discrete choice experiment (DCE) to identify optimal statements regarding a vaccination programme, including vaccine characteristics.
\end{abstract}

Methods: Girls and boys enrolled in the last two years of five middle schools in three French regions (aged 13-15 years) participated in an in-class cross-sectional self-administered internetbased study. In ten hypothetical scenarios, participants decided for or against signing up for a school-based vaccination campaign against an unnamed disease. Scenarios included different levels of four attributes: the type of vaccine-preventable disease, communication on vaccine safety, potential for indirect protection, and information on vaccine uptake among peers. One scenario was repeated with an added mention of sexual transmission.

Results: The 1,458 participating adolescents (estimated response rate: $89.4 \%$ ) theoretically accepted vaccination in $80.1 \%$ of scenarios. All attributes significantly impacted theoretical vaccine acceptance. Compared to a febrile respiratory disease, protection against cancer was motivating (odds ratio (OR) 1.29 [95\%-CI 1.09-1.52]), but not against genital warts (OR 0.91 [0.78-1.06]). Compared to risk negation ("vaccine does not provoke serious side effects"), a reference to a positive benefit-risk balance despite a confirmed side effect was strongly dissuasive (OR 0.30 [0.24-0.36]), while reference to ongoing international pharmacovigilance without any scientifically confirmed effect was not significantly dissuasive (OR 0.86 [0.711.04]). The potential for indirect protection motivated acceptance among girls but not boys (potential for eliminating the disease compared to no indirect protection, OR 1.57 [1.25-1.96]). Compared to mentioning "insufficient coverage", reporting that ">80\% of young people in other countries got vaccinated" motivated vaccine acceptance (OR 1.94 [1.61-2.35]). The notion of sexual transmission did not influence acceptance. 
Conclusion: HPV vaccine communication to adolescents can be tailored to optimise the impact of promotion efforts.

Keywords: HPV, vaccine acceptance, Discrete choice experiment, France, adolescents, communication 


\section{Introduction}

Human papillomavirus (HPV) infection is responsible for several cancers (1), including cervical cancer (CC). In France, about 3,000 new cases of CC and 1,117 deaths occurred in 2018 (2), which placed it in $11^{\text {th }}$ position in terms of frequency and $10^{\text {th }}$ in terms of mortality rate in women in 2015 (3).

HPV vaccination effectively prevents HPV infections and (pre-)cancerous cervical lesions $(4,5)$ and has been recommended for girls in France for over ten years. The current recommendation targets girls aged 11-14 years (with a catch-up up to 19 years) and will be expanded to boys starting 2021 (6). The vaccine coverage in France for 16-year-old girls has remained continuously below $30 \%$ (7), among the lowest in Europe $(8,9)$ and represents hundreds of deaths and thousands of infections which could be avoided (10). Lack of information, concerns about vaccine safety and mistrust in health authorities and new vaccines have been described as the principal barriers $(11,12)$. French studies also suggested that lack of general practitioners (GP) recommendation and perceived low effectiveness by parents play an important role (1315). Previous works using discrete choice experiments (DCE) have underlined the importance of social conformism and indirect protection effects as factors of vaccine acceptance in general $(16-18)$.

In France, HPV vaccines are accessible mainly through private medical practices and gynaecologist consultations, but also through family planning and vaccination centres. The national health insurance covers $65 \%$ of the HPV vaccine cost, and the remaining $35 \%$ are reimbursed by complementary (private or collective) insurance schemes, which cover about $95 \%$ of the French population (but $<90 \%$ of the lowest-income households)(19). School-based HPV vaccination, which in the UK (20) or Australia (21) helped achieve around 90\% coverage, occurs only in few French administrative areas. 
In this context, the PrevHPV project was designed to develop, implement and evaluate a complex intervention targeting adolescents, parents and GPs. The intervention includes a school-based education programme on HPV vaccination, a school-based vaccination campaign and a GPs motivational interviewing training.

Given the complexity of the determinants of vaccine hesitancy, the World Health Organisation (WHO) recommends the use of social marketing practices to address this issue in specific population groups (22). Conjoint experiments, and in particular discrete choice experiments (DCEs), have been increasingly used to explore users' healthcare preferences, especially regarding preventive interventions (23-25). These methods, arising from economics and mathematical psychology, allow assessing the individual and combined impact of a set of factors on a theoretical decision (26), such as choosing between two alternative treatments, or deciding whether or not to opt-in for a preventative programme (e.g., screening or vaccination). This approach thus helps to translate observational evidence into interventions and pre-testing them before implementation. Previous DCEs have studied girls' preferences on HPV vaccine characteristics such as degree/duration of protection, administration route, number of required doses, price and age at vaccination (27-29). More recently, DCEs were used to document, among other factors, the importance of social conformism, risk of side effects, and herd immunity as factors of vaccine acceptance among university students in France (16) or parents in Belgium (17). However, they have not been used to inform on adolescents' preferences regarding the content of information campaigns, which would be needed to tailor communication to adolescents' preferences.

As part of the PrevHPV project, we aimed to assess which statements around HPV vaccination had optimal effect on theoretical vaccine acceptance among adolescents to tailor the schoolbased communication, using a single profile discrete choice experiment (DCE) with opt-out. 


\section{Methods}

\section{Study design and participant inclusion}

We conducted a cross-sectional study from January $31^{\text {th }}$ to March $13^{\text {th }} 2020$ in five middle schools ("collège", Supplementary File A) located in three French regions (Grand Est, Pays de la Loire and Auvergne-Rhône-Alpes). The study population were female and male adolescents enrolled in their last two years of middle school (typically aged 13-15 years, corresponding to grades 8 and 9 in the US educational system) in public or private schools. We focused on this age range because younger adolescents are less likely to be involved in vaccine decisions, may find DCE tasks challenging, and because vaccination and human reproduction are part of those grades' curriculum. We randomly selected middle schools in participating regions and invited them to participate voluntarily. The objective was to include at least 1,000 respondents, 200 per gender and socio-economic strata as recommended in Bridges et al. (2011) (24). Data collection stopped with school closure in response to the Covid-19 epidemic, but a sufficient sample size had been reached by that time.

Participating middle schools sent study information letters to parents, who could refuse their child's participation. Adolescents received the study information in class and had the possibility to refuse or stop their participation at any time while completing the questionnaire. The selfadministered and internet-based questionnaire was hosted on the REDCap (Research Electronic Data Capture) tool $(30,31)$ and completed during class. Data collection was anonymous at all stages, and no information on the health status of respondents was collected. We obtained institutional and ethics approval from Inserm IRB (n¹9-642). 


\section{Questionnaire}

The 15-minute questionnaire comprised four parts: (i) introductory questions such as age and gender, (ii) basic information on infectious diseases and vaccines along with a brief explanation of each attribute (Supplementary File B), (iii) the discrete choice experiment and (iv) detailed questions on participants' characteristics, including attitudes on vaccination.

For the DCE, participants were asked to imagine the following situation: A vaccination campaign would be organised at their school in two weeks, during which free vaccination would be offered by a doctor during an individual consultation. Their parents would already be informed and asked for their consent. Based on one changeable set of information given to them by the school nurse, participants would need to decide whether or not to sign up for getting vaccinated during the campaign (Figure 1). In other words, the choice task was designed as a single profile DCE format with an opt-out.

\section{Attributes and levels}

We drafted a first DCE tool version based on a literature review and expert opinion. It aimed to be realistic within a communication campaign in France. This version included barriers and facilitators of vaccine acceptance: disease targeted by the vaccine, vaccine effectiveness, vaccine safety, vaccine access (free, need to consult a doctor), possibility of spacing out cancer screening for girls who got vaccinated, potential for indirect protection, vaccine acceptance rates among peers, vaccine recommendation for girls only or both genders. A panel of eight experts in epidemiology, social psychology, infectious diseases, sociology, and general practice discussed this list of attributes during a consultation meeting. The resulting revised version was reviewed by a health communication specialist to ensure that wording was accessible to lower literacy levels among adolescents. Finally, the questionnaire was tested during five qualitative 
think-aloud interviews (32), during which participants were asked to reflect aloud on their thoughts and feelings when answering the choice tasks. Modifications were made iteratively until saturation was reached (Supplementary File C). The final DCE tool included the following hypotheses and attribute (levels) (Table 1).

1) Disease (three levels): We hypothesised that mentioning prevention of a cancer that could occur in 20 years (Cancer in 20 years) was less motivating (risk too far in the future) and genital warts (Genital warts) was more motivating than an unnamed febrile respiratory disease (Respiratory disease, the reference), because of the imminent discomfort associated with genital warts.

2) Safety (four levels): We aimed at evaluating if and to which extent the information about a rare but potentially severe side effect with nevertheless a positive benefit-risk balance - a formulation regularly used by French health authorities (Benefit-risk) would decrease acceptance compared to a straight negation of serious side effects (No side effects, the reference). We also hypothesised that factual information about longstanding international surveillance of vaccine safety during which no side effect was scientifically confirmed (Scientific surveillance) would increase acceptance compared to the reference. Furthermore, we wanted to test whether explaining that there was no increase in the incidence of side effects that could be due to vaccination in other countries with a high number of vaccinated persons (Safety other countries), would increase acceptance compared to the reference (straight negation). Our assumption was that straight negation could amplify mistrust toward authorities and thus vaccination (33).

3) Indirect Protection (three levels): Using exclusively individual protection as the reference (Individual protection only), we aimed at quantifying by how much acceptance would increase with the information that vaccination blocks the transmission 
to other persons (Protects others), or the potential of disease elimination in case of high coverage (Elimination).

4) Coverage (four levels): Using the notion of insufficient coverage (Not enough) - a formulation frequently used in vaccine communication - as the reference, we aimed to evaluate the extent to which nudging information about low coverage (Already one third), or social conformism about high coverage among French adolescents (Most students) and in other countries (Other countries 80\%) could improve acceptance.

To specifically test whether mentioning sexual transmission of the pathogen would decrease acceptance of vaccination among adolescents, we used it as an additional attribute (Sexual Transmission, one level), only present in one choice task (34).

\section{Experimental design}

These four attributes provided 128 combinations of attributes' levels in a full factorial design. We used NGENE® software to generate a 36-profile efficient design for a multinomial logit model with non-informative priors for attributes' level parameters and a standard error of 2 for the random model intercept (thus allowing for heterogeneity in stated vaccination uptake). We specified a utility function allowing estimation of all main effects and two pre-specified interaction effects (Indirect_Elimination * Coverage_Moststudents; Indirect_Elimination * Coverage_Othercountries $80 \%$ ) that were judged particularly relevant based on a priori assumption and think-aloud results. This partition was divided into four versions of nine scenarios, or choice tasks, each.

In each version, we then repeated one of the choice tasks with the addition of the Sexual Transmission attribute (34). Thus, the final design comprised four sets of ten scenarios (40 unique scenarios) randomly assigned to backward or forward order to each respondent (available in Supplementary File D). 


\section{Statistical analyses}

We described the distribution of participant characteristics and estimated their association with theoretical vaccine acceptance using a full multivariate logistic regression model.

We estimated preference weights for vaccine acceptance using random intercept logit models (through inclusion of a random effect at the respondent level) and expressed as odds ratios for each attribute level (24). This multi-level analysis allowed for random (unobserved) variation in vaccination acceptance thus accounting for heterogeneity in adolescent's preferences. Because of the panel nature of the data (multiple choices per subject), a fixed (instead of random) effects specification could have been used. Models with the fixed effects specification yielded similar results (Hausman test comparing fixed and random effects specification not significantly different from 0). The main analyses included the four main attributes as independent variables. To explore signals of effect modification by gender, we conducted indepth stratification by this variable. We conducted further stratified analyses by age group, parental education level and foreign language spoken at home.

We calculated average marginal effects to estimate average changes in probability of vaccine acceptance for each attribute level. In a sensitivity analysis, we excluded participants whose decision was uniformly positive or negative (i.e., always accepting or refusing the vaccine in all hypothetical scenarios). Respondents with uniform decisions do not provide any information about their underlying preferences for the attributes of vaccination programmes. Marginal effects can therefore inform on the attribute's impact on vaccine decision either among the overall population or specifically among (hesitant) persons with variable decisions.

Observed determinants of preference heterogeneity were analysed using interaction models (attributes*individual characteristics, variables were included in the final model if they significantly interacted with one or more attributes at the 0.10 level). Finally, to assess the 
impact of the additional attribute' sexual transmission' on vaccine acceptance, the proportion of adolescents agreeing to vaccinate in the scenario including/excluding this information were compared using equality of proportion tests. All analyses were conducted on Stata 15 (StataCorp LP, College Station, Texas).

\section{Results}

\section{Participant characteristics}

Among 1,552 respondents (estimated response rate 89.4\%), 1,458 participants with valid and complete questionnaires were included (Figure 2). The mean age of study participants was 13.8 (standard deviation 0.76) years, with 53.4\% girls (Table 2). About $40 \%$ declared that their mother or father had completed post-secondary education, while about $37 \%$ did not know their parents' educational level. One-quarter of participants declared that they also spoke another language than French at home.

Three-quarters of respondents were in favour of vaccination in general, while a large part did not know their immunisation status (between $35.5 \%$ for DTaP-IPV and $75.1 \%$ for meningococcal C vaccine). Declared HPV immunisation status among girls was $27.2 \%$, with $47.6 \%$ being unaware of their status. Over $90 \%$ agreed that vaccination was useful and $80 \%$ that it could protect others. One third declared being scared of injections, while one quarter was scared of the substances in the vaccine. About half stated that finding trustworthy information on vaccination was easy, while $19.6 \%$ found it difficult.

\section{Stated preferences}

Vaccination was theoretically accepted in $80.1 \%$ (range $64.0 \%-87.7 \%$ ) of scenarios

(Supplementary File D). Uniform decisions across all scenarios were made by $51.2 \%$ of participants $(n=747)$, with $6.0 \%(n=88)$ always refusing and $45.2 \%(n=659)$ always accepting 
vaccination. When removing participants with uniform decisions, vaccination was theoretically accepted in $71.6 \%$ of scenarios. Response time was similar for uniform and variable responders (Supplementary File E). Theoretical acceptance varied between schools from $66.8 \%$ to $84.7 \%$. Individual characteristics significantly associated with theoretical vaccine acceptance were the school, a favourable attitude towards vaccination in general, perceived usefulness of vaccination, only French spoken with parents, stated HPV vaccine status and perceived ease of obtaining trustworthy information (Table 2).

Most attributes and attribute levels contributed significantly to theoretical vaccine decision (Table 3). Other attributes being equal, cancer prevention motivated girls more than the febrile respiratory disease (OR: 1.39, 95\%-CI [1.11,1.75]) or genital warts prevention (OR cancer vs warts: $1.37[1.09,1.73])$. This attribute was not statistically significant among boys. Regarding safety, the level "Scientific surveillance" was not significantly different from "No side effect" (OR: 0.86 [0.71-1.04]). Both levels "Safety other countries" and "Benefit/risks" were strongly demotivating (OR: 0.30 [0.24-0.36] for both levels). Any information on indirect protection was motivating for girls (OR for Elimination: 1.57 [1.25;1.96]), but not for boys (OR: 1.19 $[0.92 ; 1.55])$. Informing on low coverage with a nudge ("already one third") was significantly more motivating than judging it as insufficient (OR 1.48 [1.23;1.78]). Strong social conformism appeared ("most students" OR 1.98 [1.64;2.38] and "other countries 80\%" OR 1.94 [1.612.35]). Effects were similar in both gender groups. We did not find any statistically significant interaction between Indirect Protection and Coverage attributes in the main sample or by gender (Table 3).

Adding the information on sexual transmission did not significantly influence acceptance (77.8 $\%$ vs $76.5 \%$ acceptance, $\mathrm{p}=0.567$ ), with a slight but not significant trend for increased acceptance among boys (Table 4 ). 
When stratifying on individual characteristics, lower and insignificant preference weights for Elimination were observed among boys compared to girls, adolescents aged 15-17 years compared to the other age groups, and to a lesser extent, lower parental educational level and the presence of a foreign language spoken at home. However, confidence intervals of subgroups overlapped. (Figure 3).

We found several significant interactions between attributes and individual characteristics. For example, adolescents agreeing that it is useful to get vaccinated were more sensitive to the mention of "cancer" from the disease attribute (stronger positive effect). For the safety attribute, older adolescents (14 and 15 and older) were less sensitive to the mention of a positive benefit/risk balance compared to younger adolescents (weaker negative effect). Finally, adolescents declaring being "in favour of vaccination" were more sensitive to the high coverage level among their peers or in other countries (stronger positive effect) compared to adolescents declaring not being in favour of vaccination (Supplementary File F).

In sensitivity analyses restricted to participants with varying decisions, we found an average 23 percentage point (pp) decrease in the probability of vaccine acceptance with the Benefit-risk balance attribute level ( $8 \mathrm{pp}$ decrease for the overall sample) and a $14 \mathrm{pp}$ increase ( $5 \mathrm{pp}$ for the overall sample) with information on the high coverage achieved in countries like England and Portugal (Figure 4 and Supplementary File G).

\section{Discussion}

In this DCE study which evaluated preferences around communication on school-based HPV vaccination among French adolescents, we found that statements on vaccine safety and social conformism had the greatest potential to influence vaccine acceptance in both genders while mentioning the potential for indirect protection and disease elimination had a strong positive impact only among girls. Presenting a low coverage with a nudge was more effective than 
referring to insufficient coverage. Prevention of cancer led to a higher acceptance among girls than of genital warts, while the notion of sexual transmission had no substantial impact in either gender.

The Safety attribute had the strongest negative impact on vaccine acceptance. Vaccine safety doubts are in most populations associated with vaccine hesitancy and mistrust $(11,35)$. DCE generally investigate this aspect using increasing probabilities of serious side effects (28). While a French national analysis has described an association of HPV vaccine with GuillainBarre syndrome (36), WHO considers HPV vaccines as safe given the fact that the French signal could not be scientifically confirmed by reproducing the results in other countries. We investigated how to best communicate on this complex situation. Explaining worldwide surveillance efforts with no scientific confirmation of a serious side effect appears to be most reassuring, while the notion of benefice-risk balance rather emphasised the existence of a severe side effect. Plain negation of serious side effects, used as the reference in our DCE tool, do not appear appropriate as it omits the risk of anaphylactic shock. Strong negation of serious side effects has also been shown to amplify mistrust toward information sources on vaccination (33). Contrary to our hypothesis that evoking an absence of increased risk in countries with high vaccine coverage would be motivating, it caused similar negative impact as referring to a positive benefit-risk balance despite a severe side effect. It is likely that the wording led respondents to think that the serious side effect was confirmed. Finally, the statement introducing a rare but serious side effect with a maintained positive benefit-risk balance likely should be restricted to scientific considerations and not used in public communication.

Previous studies in France and Belgium $(16,37)$ have described the importance of communicating on high coverage levels while avoiding the notion of "insufficient coverage". The period of adolescence is particularly prone to social conformism (38), which should be integrated into vaccine communication. 
Long-term prevention of a cancer had higher motivating potential among girls than a febrile respiratory disease. Harper et al. (2014) investigated decisional satisfaction of women around HPV vaccination and described greater value in getting vaccinated for cervical cancer prevention compared to genital warts protection (39). However, Brown et al. (2014), who conducted a DCE on HPV among American girls, found that mentioning protection against genital warts in addition to cancer would be most motivating (29). By contrast, Wang et al. (2017) found among Australian adolescents that the mention of STI vaccines was only marginally motivating compared to vaccination against a chronic or life-threatening illness (40). In our study, neither the notion of sexual transmission nor genital warts affected vaccine acceptance significantly. Focusing on cancer prevention instead of sexual health could be more effective and efficient for communication on HPV vaccination.

The motivating role of indirect protection has been described in a previous DCE among French university students (16) but was not found among Australian teenagers (40). Our results suggest that adolescent girls could be more motivated than boys by arguments calling for altruism or collective engagement, which is supported by the literature among adults $(41,42)$. However, among US male college students, altruistic motives increased vaccine acceptance (43). More research is needed to understand better the gender-specific aspects of HPV vaccine decision among adolescents and young adults.

Our results suggest that optimised statements on vaccination could increase motivation for vaccination among adolescents. Minors are involved in the vaccine decision-making process (12), and their motivation could also positively impact parental vaccine decisions concerning their children vaccination $(44,45)$. DCE only address theoretical vaccine acceptance, and the observed effect sizes cannot be readily extrapolated to gains in vaccine coverage, given the complexity of families' vaccine decision and access barriers. However, under the assumption that stated vaccination intentions match actual behaviour, we could approximate that an 
increase in vaccine coverage between 5 and 15 percentage points could be achieved if a few simple principles were followed when communicating on HPV vaccination during schoolbased campaigns: avoiding the notion of "insufficient coverage" and communicating instead on high coverage in neighbouring countries; referring to worldwide scientific consensus and efforts to ensure vaccine safety, and to the potential for eliminating cancers caused by HPV.

\section{Study limitations}

Our study presents several limitations. First, the prevalence of theoretical vaccine acceptance in our study was high compared to the actual HPV vaccine coverage, an observation already made by a Dutch DCE study (28). As in all stated preferences studies, interpretation of results must consider the hypothetical nature of decisions. Participants may have chosen to sign up for vaccination knowing that 1) it was a fictional exercise, 2) they could change their mind between the registration and the vaccination campaign, and 3) in real life, the opinion of their parents would have been more important than their own. As our DCE tool did not specify HPV vaccine, participants may have a higher vaccine acceptance than if HPV vaccine had been mentioned. Also, intention is known to represent only $30 \%$ of variation in behaviour (46). However, in our sample, French adolescents were favourable towards vaccination in general, at a similar rate as French adults (47), and the difference between adolescents' preferences and coverage may also be explained by parents' negative opinions on HPV vaccine and/or lack of vaccine recommendation by general practitioners.

Second, our sample is not representative of French adolescents, and no prevalence of attitudes can thus be estimated. However, our sample included a variety of socio-economic settings such that stratified analyses could provide estimations in subgroups. Besides, because of school closure in March 2020 due to the Covid-19 outbreak, we could not include a larger variety of 
middle schools and geographic regions. Average theoretical vaccine acceptance varied across middle schools, which could be due to uncontrolled local factors, such as a school effect, for example, if students had recently been exposed to training on immunisation or rumours on vaccine safety. Extrapolation beyond our sample and beyond the French context should be made with caution.

Third, although we carefully selected the attributes through a literature review, experts' interviews and think-aloud tests, our experiment is limited to a school-based setting and additional essential attributes may be missing. The fact that about half of participants made (mostly positive) uniform decisions independently of attributes calls for further analysis. Other DCE studies on adolescents described fewer than $18 \%$ uniform responders $(29,48)$, which could be explained by our objective to inform communication, not to evaluate the impact of extreme constellations (high price, high risk of side effects). This could also be explained by the binary (yes/no) response format, whereas previous studies used pairwise choice tasks with opt-out. Response time was similar for uniform and variable responders, meaning that uniform responders actually provided thoughtful responses. It is thus likely that included attributes did not alter their decision.

\section{Conclusion}

Our results suggest that appropriate statements on safety profile, referring to high coverage in other countries, cancer prevention (instead of genital warts), potential for protecting others and disease elimination can motivate HPV vaccine acceptance among French adolescents. In a country where HPV vaccine coverage has consistently been below $30 \%$, increasing HPV acceptability is challenging. Statements which could motivate adolescents to get vaccinated thus represent an important tool to rely on in vaccination promotion campaigns. The PrevHPV 
project will allow testing those statements as part of a school-based interventional study aiming at increasing HPV vaccine coverage, especially with the future extension of HPV vaccine recommendation to boys.

\section{Competing interests}

The authors declare that they have no competing interests that could have appeared to influence the work reported in this paper.

\section{Author contributions}

JM, IB, JS and JR conceived the original idea. JM, JS and SC designed the study. FJ, ASDB, AG and SC organised the data collection. SC conducted the analyses and wrote the manuscript under JM and JS's supervision. NT, BG, MM, SB and AG contributed to the data interpretation. All authors revised and approved the manuscript.

\section{Acknowledgement}

We thank the middle schools who accepted administering the questionnaire during class time as well as all the students who participated. We thank the PrevHPV Consortium in which this study was conducted, in particular Amandine Gagneux-Brunon (CHU de Saint-Etienne), Serge Gilberg (Université de Paris), Karine Chevreul (INSERM UMR 1123 ECEVE), and Stéphanie Bonnay (Université de Lorraine). Moreover, we thank Julie Kalecinski, Anne-Sophie Barret, Manon-Océane Taravella and Marie Sanchez for their help with questionnaire formulation and implementation. 


\section{Funding}

The study was part of the PrevHPV project, sponsored by Institut national de la santé et de la recherche médicale (INSERM), with financial support from ITMO Cancer and ITMO Santé publique from AVIESAN (Alliance Nationale pour les Sciences de la Vie et de la Santé/ National Alliance for Life Sciences \& Health) within the framework of the Cancer Plan 20142019. The funding sources had no involvement in the study design, the collection, analysis and interpretation of data; in the writing and in the decision to submit the article for publication.

\section{Supplementary material captions}

Supplementary File A - Brief description of middle schools' characteristics

Supplementary File B - Information given before the choice tasks. (authors' translation)

Supplementary File C -Modifications made on the attributes and levels

Supplementary File D - Average percentage of vaccine acceptance for each scenario; from lowest to highest

Supplementary File E - Response Time by Uniform/varied decision

Supplementary File F - Results of random intercept logit models of vaccination acceptance including interactions between attributes and individual characteristics

Supplementary File G - Vaccination acceptance in the "Overall sample" and the "Varied decision only" subsample

\section{References}

1. Bansal A, Singh M, Rai B. Human papillomavirus-associated cancers: A growing 
global problem. Int J Appl Basic Med Res. 2016;6(2):84.

2. Hamers FF, Woronoff A-S, Réseau français des registres de cancers Francim. Cancer du col de l'utérus en France : tendances de l'incidence et de la mortalité jusqu'en 2018. Bull Epidémiol Hebd [Internet]. 2019;22-23:410-6. Available from: http://beh.santepubliquefrance.fr/beh/2019/22-23/2019_22-23_1.html

3. Institut national du cancer. Les cancers en France - Les données - Edition 2015 [Internet]. Boulogne; 2015. Available from: www.e-cancer.fr

4. Garland SM, Kjaer SK, Muñoz N, Block SL, Brown DR, Dinubile MJ, et al. Impact and effectiveness of the quadrivalent human papillomavirus vaccine: A systematic review of 10 years of real-world experience [Internet]. Vol. 63, Clinical Infectious Diseases. 2016 [cited 2020 Apr 20]. p. 519-27. Available from: http://www.ncbi.nlm.nih.gov/pubmed/27230391

5. Lei J, Ploner A, Elfström KM, Wang J, Roth A, Fang F, et al. HPV Vaccination and the Risk of Invasive Cervical Cancer. N Engl J Med [Internet]. 2020 Oct 1;383(14):13408. Available from: http://www.nejm.org/doi/10.1056/NEJMoa1917338

6. Ministère des Solidarités et de la Santé. Le calendrier des vaccinations 2020 [Internet]. 2020 [cited 2020 Apr 21]. Available from: https://solidarites-sante.gouv.fr/preventionen-sante/preserver-sa-sante/vaccination/calendrier-vaccinal

7. Fonteneau L, Barret A-S, Levy Bruhl D. Évolution de la couverture vaccinale du vaccin contre le papillomavirus en France - 2008-2018. Bull Epidémiol Hebd. 2019;22-23:424-30.

8. Sheikh S, Biundo E, Courcier S, Damm O, Launay O, Maes E, et al. A report on the status of vaccination in Europe. Vol. 36, Vaccine. Elsevier Ltd; 2018. p. 4979-92. 
9. Nguyen-Huu N-H, Thilly N, Derrough T, Sdona E, Claudot F, Pulcini C, et al. Human papillomavirus vaccination coverage, policies, and practical implementation across Europe. Vaccine [Internet]. 2020 Feb;38(6):1315-31. Available from: https://doi.org/10.1016/j.vaccine.2019.11.081

10. Uhart M, Adam M, Dahlab A, Bresse X. Loss of chance associated with sub-optimal HPV vaccination coverage rate in France. Papillomavirus Res. 2017 Jun 1;3:73-9.

11. Karafillakis E, Simas C, Jarrett C, Verger P, Peretti-Watel P, Dib F, et al. HPV vaccination in a context of public mistrust and uncertainty: a systematic literature review of determinants of HPV vaccine hesitancy in Europe. Hum Vaccines Immunother. 2019 Aug 3;15(7-8):1615-27.

12. Gowda C, Schaffer SE, Dombkowski KJ, Dempsey AF. Understanding attitudes toward adolescent vaccination and the decision-making dynamic among adolescents, parents and providers. BMC Public Health. 2012 Jul 7;12(1):1-10.

13. Amessi L. Connaissances sur les infections génitales à HPV et couverture vaccinale HPV des élèves d'un collège à Paris. 2016.

14. Ecollan M. Connaissances et facteurs associés à la vaccination anti-HPV chez les parents des élèves de deux collèges parisiens. 2016.

15. Verrier F, Gautier A, Quelet S, Bonmarin I. Human papillomavirus infections: influence of perceptions of disease and vaccine on immunization status. Bull Epidémiol Hebd [Internet]. 2019;(22/23):450-6. Available from: http://beh.santepubliquefrance.fr/beh/2019/22-23/pdf/2019_22-23_6.pdf

16. Seanehia J, Treibich C, Holmberg C, Müller-Nordhorn J, Casin V, Raude J, et al. Quantifying population preferences around vaccination against severe but rare diseases: 
A conjoint analysis among French university students, 2016. Vaccine [Internet]. 2017 May;35(20):2676-84. Available from:

https://linkinghub.elsevier.com/retrieve/pii/S0264410X17304383

17. Verelst F, Willem L, Kessels R, Beutels P. Individual decisions to vaccinate one's child or oneself: A discrete choice experiment rejecting free-riding motives. Soc Sci Med [Internet]. 2018 Jun;207(May):106-16. Available from: https://linkinghub.elsevier.com/retrieve/pii/S0277953618302053

18. Verelst F, Kessels R, Delva W, Beutels P, Willem L. Drivers of vaccine decisionmaking in South Africa: A discrete choice experiment. Vaccine [Internet]. 2019 Apr;37(15):2079-89. Available from: https://linkinghub.elsevier.com/retrieve/pii/S0264410X19302634

19. Perronnin M, Louvel A. La complémentaire santé en $2014: 5 \%$ de non-couverts et 12 $\%$ parmi les $20 \%$ les plus pauvres. Quest d'économie la santé [Internet]. 2018;229:16. Available from: http://www.irdes.fr/recherche/questions-d-economie-de-lasante/229-la- complementaire-sante-en-2014.pdf

20. Sinka K, Kavanagh K, Gordon R, Love J, Potts A, Donaghy M, et al. Achieving high and equitable coverage of adolescent HPV vaccine in Scotland. J Epidemiol Community Health [Internet]. 2014 [cited 2020 Aug 21];68(1):57-63. Available from: https://pubmed.ncbi.nlm.nih.gov/23986492/

21. Patel C, Brotherton JML, Pillsbury A, Jayasinghe S, Donovan B, Macartney K, et al. The impact of 10 years of human papillomavirus (HPV) vaccination in Australia: What additional disease burden will a nonavalent vaccine prevent? Eurosurveillance. 2018;23(41):30-40.

22. Nowak GJ, Gellin BG, MacDonald NE, Butler R, Eskola J, Liang X, et al. Addressing 
vaccine hesitancy: The potential value of commercial and social marketing principles and practices. Vaccine. 2015;33(34):4204-11.

23. de Bekker-Grob EW, Ryan M, Gerard K. Discrete choice experiments in health economics: a review of the literature. Health Econ [Internet]. 2012 Feb [cited 2020 May 5];21(2):145-72. Available from: http://doi.wiley.com/10.1002/hec.1697

24. Bridges JFP, Hauber AB, Marshall D, Lloyd A, Prosser LA, Regier DA, et al. Conjoint Analysis Applications in Health — a Checklist: A Report of the ISPOR Good Research Practices for Conjoint Analysis Task Force. Value Heal [Internet]. 2011 Jun;14(4):403-13. Available from: https://linkinghub.elsevier.com/retrieve/pii/S1098301510000835

25. Soekhai V, de Bekker-Grob EW, Ellis AR, Vass CM. Discrete Choice Experiments in Health Economics: Past, Present and Future. Pharmacoeconomics [Internet]. 2019 Feb 13 [cited 2020 Jul 30];37(2):201-26. Available from: https://pubmed.ncbi.nlm.nih.gov/30392040/

26. Ryan M. Using conjoint analysis to take account of patient preferences and go beyond health outcomes: An application to in vitro fertilisation. Soc Sci Med [Internet]. 1999 Feb [cited 2020 May 5];48(4):535-46. Available from: http://www.ncbi.nlm.nih.gov/pubmed/10075178

27. Hofman R, De Bekker-Grob EW, Richardus JH, De Koning HJ, Van Ballegooijen M, Korfage IJ. Have preferences of girls changed almost 3 years after the much debated start of the HPV vaccination program in the Netherlands? A discrete choice experiment. PLoS One. 2014;9(8).

28. de Bekker-Grob EW, Hofman R, Donkers B, van Ballegooijen M, Helmerhorst TJMM, Raat H, et al. Girls' preferences for HPV vaccination: A discrete choice experiment. 
Vaccine [Internet]. 2010;28(41):6692-7. Available from:

http://dx.doi.org/10.1016/j.vaccine.2010.08.001

29. Brown DS, Poulos C, Johnson FR, Chamiec-Case L, Messonnier ML. Adolescent Girls’ Preferences for HPV Vaccines: A Discrete Choice Experiment. In: Preference Measurement in Health (Advances in Health Economics and Health Services Research) [Internet]. Emerald Group Publishing Limited; 2014. p. 93-121. Available from: https://www.emerald.com/insight/content/doi/10.1108/S0731219920140000024002/full/html

30. Harris PA, Taylor R, Thielke R, Payne J, Gonzalez N, Conde JG. Research electronic data capture (REDCap)-A metadata-driven methodology and workflow process for providing translational research informatics support. J Biomed Inform. 2009 Apr 1;42(2):377-81.

31. Harris PA, Taylor R, Minor BL, Elliott V, Fernandez M, O’Neal L, et al. The REDCap consortium: Building an international community of software platform partners. Vol. 95, Journal of Biomedical Informatics. Academic Press Inc.; 2019. p. 103208.

32. Ryan M, Watson V, Entwistle V. Rationalising the "irrational": A think aloud study of discrete choice experiment responses. Health Econ [Internet]. 2009 [cited 2020 Aug 18];18(3):321-36. Available from: https://pubmed.ncbi.nlm.nih.gov/18651601/

33. Betsch C, Sachse K. Debunking vaccination myths: Strong risk negations can increase perceived vaccination risks. Heal Psychol [Internet]. 2013 [cited 2015 Sep 1];32(2):146-55. Available from: http://www.ncbi.nlm.nih.gov/pubmed/22409264

34. Mansfield C, Sutphin J, Boeri M. Assessing the impact of excluded attributes on choice in a discrete choice experiment using a follow-up question. Health Econ [Internet]. 2020 Jul 6 [cited 2020 Aug 18];hec.4124. Available from: 
https://onlinelibrary.wiley.com/doi/abs/10.1002/hec.4124

35. Karafillakis E, Larson HJ. The benefit of the doubt or doubts over benefits? A systematic literature review of perceived risks of vaccines in European populations. Vaccine [Internet]. 2017;35(37):4840-50. Available from: http://dx.doi.org/10.1016/j.vaccine.2017.07.061

36. Miranda S, Chaignot C, Hristophe, Collin C, Dray-Spira R, Weill A, et al. Human papillomavirus vaccination and risk of autoimmune diseases: A large cohort study of over 2million young girls in France. Vaccine [Internet]. 2017 Aug 24 [cited 2020 Apr 30];35(36):4761-8. Available from: http://www.ncbi.nlm.nih.gov/pubmed/28750853

37. Godinot LD, Sicsic J, Lachâtre M, Abiteboul D, Rouveix E, Raude J, et al. Quantifying preferences around vaccination against frequent, mild disease with risk for vulnerable persons: A discrete choice experiment among French hospital health care workers [Internet]. 2020 Nov [cited 2020 Nov 23]. Available from: https://halshs.archivesouvertes.fr/halshs-03008549

38. Dayan J, Guillery-Girard B. Conduites adolescentes et développement cérébral : psychanalyse et neurosciences. Adolescence [Internet]. 2011;77(3):479. Available from: https://www.cairn-int.info/load_pdf.php?ID_ARTICLE=E_ADO_077_0479

39. Harper DM, Irons BB, Alexander NM, Comes JC, Smith MS, Heutinck MA, et al. Quantifying the decisional satisfaction to accept or reject the human papillomavirus (HPV) vaccine: A preference for cervical cancer prevention. PLoS One. 2014 Feb $14 ; 9(2)$.

40. Wang B, Chen G, Ratcliffe J, Afzali HHA, Giles L, Marshall H. Adolescent values for immunisation programs in Australia: A discrete choice experiment. PLoS One [Internet]. 2017;12(7):e0181073. Available from: 
https://journals.plos.org/plosone/article/file?id=10.1371/journal.pone.0181073\&type=p rintable

41. Zarbatany L, Hartmann DP, Gelfand DM, Vinciguerra P. Gender Differences in Altruistic Reputation. Are They Artifactual? Dev Psychol [Internet]. 1985 Jan [cited 2020 Jun 22];21(1):97-101. Available from: /record/1985-14218-001

42. Braaas-Garza P, Capraro V, Rascon E. Gender Differences in Altruism on Mechanical Turk: Expectations and Actual Behaviour. SSRN Electron J [Internet]. 2018 Jun 23 [cited 2020 Jun 22]; Available from: https://papers.ssrn.com/abstract=2796221

43. Bonafide KE, Vanable PA. Male Human Papillomavirus Vaccine Acceptance Is Enhanced by a Brief Intervention that Emphasises Both Male-Specific Vaccine Benefits and Altruistic Motives. Sex Transm Dis [Internet]. 2015 Feb 2 [cited 2020 Jun 19];42(2):76-80. Available from:

http://content.wkhealth.com/linkback/openurl?sid=WKPTLP:landingpage\&an=000074

\section{$35-201502000-00005$}

44. Berenson AB, Laz TH, Hirth JM, McGrath CJ, Rahman M. Effect of the decisionmaking process in the family on HPV vaccination rates among adolescents 9-17 years of age. Hum Vaccin Immunother [Internet]. 2014 Jul 7;10(7):1807-11. Available from: https://www.tandfonline.com/doi/full/10.4161/hv.28779

45. Chang J, Ipp LS, de Roche AM, Catallozzi M, Breitkopf CR, Rosenthal SL. Adolescent-Parent Dyad Descriptions of the Decision to Start the HPV Vaccine Series. J Pediatr Adolesc Gynecol [Internet]. 2018 Feb;31(1):28-32. Available from: https://linkinghub.elsevier.com/retrieve/pii/S1083318817304771

46. Sheeran P. Intention-Behavior Relations: A Conceptual and Empirical Review. Eur Rev Soc Psychol [Internet]. 2002 Jan 1 [cited 2020 Nov 19];12(1):1-36. Available 
from: https://www.tandfonline.com/doi/abs/10.1080/14792772143000003

47. Gautier A, Chemlal K, Jestin C, le groupe Baromètre santé 2016. Adhésion à la vaccination en France : résultats du Baromètre santé 2016. Bull Epidemiol Hebd. 2017;Hors-série(21-7):339-44.

48. Marshall HS, Chen G, Clarke M, Ratcliffe J. Adolescent, parent and societal preferences and willingness to pay for meningococcal B vaccine: A Discrete Choice Experiment. Vaccine [Internet]. 2016 Jan 27 [cited 2020 Jul 10];34(5):671-7. Available from: http://dx.doi.org/10.1016/j.vaccine.2015.11.075 
Table 1: Attributes and levels retained for the discrete choice experiment for a school-based vaccination campaign

\begin{tabular}{|c|c|c|c|}
\hline Attributes & Levels (labels) & Levels (short definition) & Assumption to be tested \\
\hline \multirow[t]{3}{*}{ Disease } & Respiratory disease & The vaccine can protect against a disease with high fever and breathlessness. & Reference \\
\hline & Cancer in 20 years & The vaccine can protect against a cancer, which could occur in 20 years from now. & $\mathrm{H}_{1}: \mathrm{OR}<1$ \\
\hline & Genital warts & The vaccine can protect against genital warts. & $\mathrm{H}_{2}: \mathrm{OR}>1$ \\
\hline \multirow[t]{4}{*}{ Safety } & No side effect & The vaccine does not cause serious side effects. & Reference \\
\hline & $\begin{array}{l}\text { Scientific } \\
\text { surveillance }\end{array}$ & $\begin{array}{l}\text { The vaccine safety has been monitored for more than } 10 \text { years worldwide. No serious side effect } \\
\text { has been scientifically confirmed. }\end{array}$ & $\mathrm{H}_{3}: \mathrm{OR}>1$ \\
\hline & Safety other countries & $\begin{array}{l}\text { In countries where most adolescents are vaccinated, the risk of a serious side effect that could be } \\
\text { due to vaccination has not increased. }\end{array}$ & $\mathrm{H}_{4}: \mathrm{OR}>1$ \\
\hline & Benefit/risk & $\begin{array}{l}\text { The vaccine can only in rare occasion cause a serious side effect, but the benefit from } \\
\text { vaccination are much greater than its risk. }\end{array}$ & $\mathrm{H}_{5}: \mathrm{OR}<1$ \\
\hline \multirow{3}{*}{$\begin{array}{l}\text { Indirect } \\
\text { Protection }\end{array}$} & Protects only you & The vaccine protects only you. & Reference \\
\hline & Protects others & By getting vaccinated, you can avoid transmitting the infection to other persons. & $\mathrm{H}_{6}: \mathrm{OR}>1$ \\
\hline & Elimination & $\begin{array}{l}\text { By vaccinating most young people of your age, one can make the disease disappear from the } \\
\text { population. }\end{array}$ & $\mathrm{H}_{7}: \mathrm{OR}>1$ \\
\hline \multirow[t]{2}{*}{ Coverage } & Not enough & Not enough students of your school have registered to get vaccinated. & Reference \\
\hline & Already one third & Already one third of students of your school have registered to get vaccinated. & $\mathrm{H}_{8}: \mathrm{OR}>1$ \\
\hline
\end{tabular}


(additional

attribute)

Elimination*most student

$\mathrm{OR}<1$ if free-riding 
Table 2: Characteristics of study participants

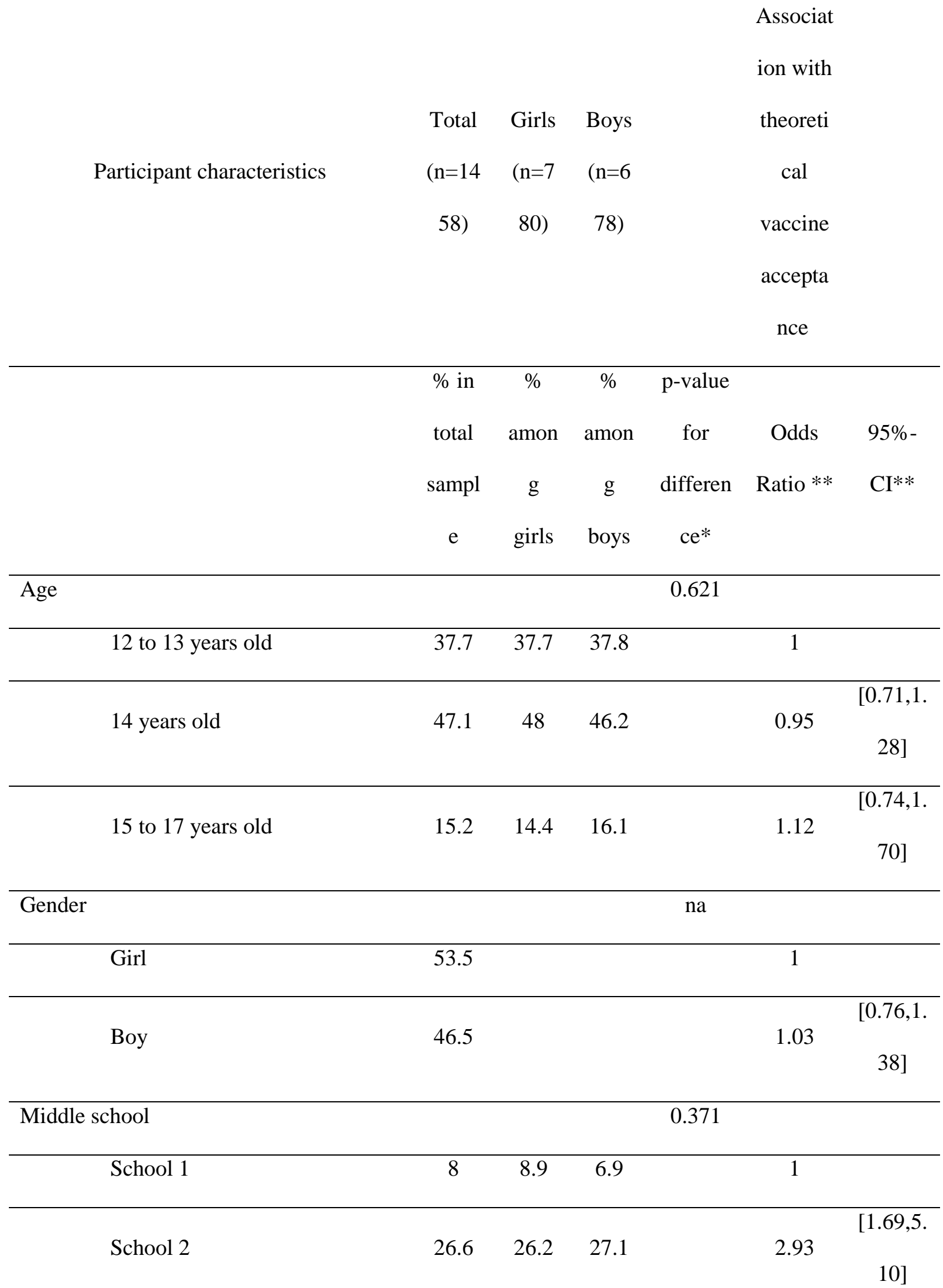


School 3

$\begin{array}{lll}10.8 & 11 \quad 10.5\end{array}$

$[0.68,2$.

31]

$[1.94,5$.

School 4

$\begin{array}{lll}28 & 29 & 26.8\end{array}$

3.32

70]

$[1.46,4$.

School 5

$26.7 \quad 25 \quad 28.6$

2.51

31]

\begin{tabular}{ccccccc}
\hline In favour of vaccination (binary) & \multicolumn{7}{c}{0.122} \\
\hline Disagree or I do not know & 23.5 & 25.1 & 21.7 & 1 & \\
\hline Agree or strongly agree & 76.5 & 74.9 & 78.3 & 4.81 & 83.38,6. \\
\hline
\end{tabular}

Education level of the parents

Inferior or equal to French

baccalaureat

$\begin{array}{lllll}19.2 & 19.2 & 19.2 & 0.279 & 1\end{array}$

Superior to French baccalaureat

for at least one parent

$\begin{array}{llll}50.7 & 49 & 52.7 & 0.86\end{array}$

$[0.59,1$.

\begin{tabular}{ccccccc}
\hline $\begin{array}{c}\text { Superior to French baccalaureat } \\
\text { for at least one parent }\end{array}$ & 50.7 & 49 & 52.7 & 0.86 & {$[0.59,1$.} \\
& & & & & $25]$ \\
\hline I do not know, non-applicable & 30.1 & 31.8 & 28.2 & 0.84 & {$[0.56,1$.} \\
\end{tabular}

\begin{tabular}{|c|c|c|c|c|c|}
\hline \multirow{2}{*}{$\begin{array}{c}\text { Language spoken with parents } \\
\text { Only French }\end{array}$} & \multicolumn{5}{|c|}{0.028} \\
\hline & 75.3 & 77.6 & 72.6 & 1 & \\
\hline Also another language & 24.7 & 22.4 & 27.4 & 0.53 & $\begin{array}{c}{[0.38,0 .} \\
73]\end{array}$ \\
\hline Stated Tdap-IPV vaccine status & \multicolumn{5}{|c|}{0.773} \\
\hline No & 4.3 & 4 & 4.7 & 1 & \\
\hline I do not know & 35.5 & 35.8 & 35.1 & 1.00 & $\begin{array}{c}{[0.41,2 .} \\
40]\end{array}$ \\
\hline Yes & 60.2 & 60.2 & 60.2 & 1.22 & {$[0.53,2$.} \\
\hline
\end{tabular}




\begin{tabular}{lcccccc}
\hline No & 6 & 4.9 & 7.3 & & 1 & \\
\hline I do not know & 44.6 & 43.8 & 45.5 & & 1.30 & {$[0.59,2$.} \\
& & & & & $86]$ \\
\hline Yes & 49.4 & 51.3 & 47.3 & 1.47 & {$[0.70,3$.} \\
& & & & & $08]$
\end{tabular}

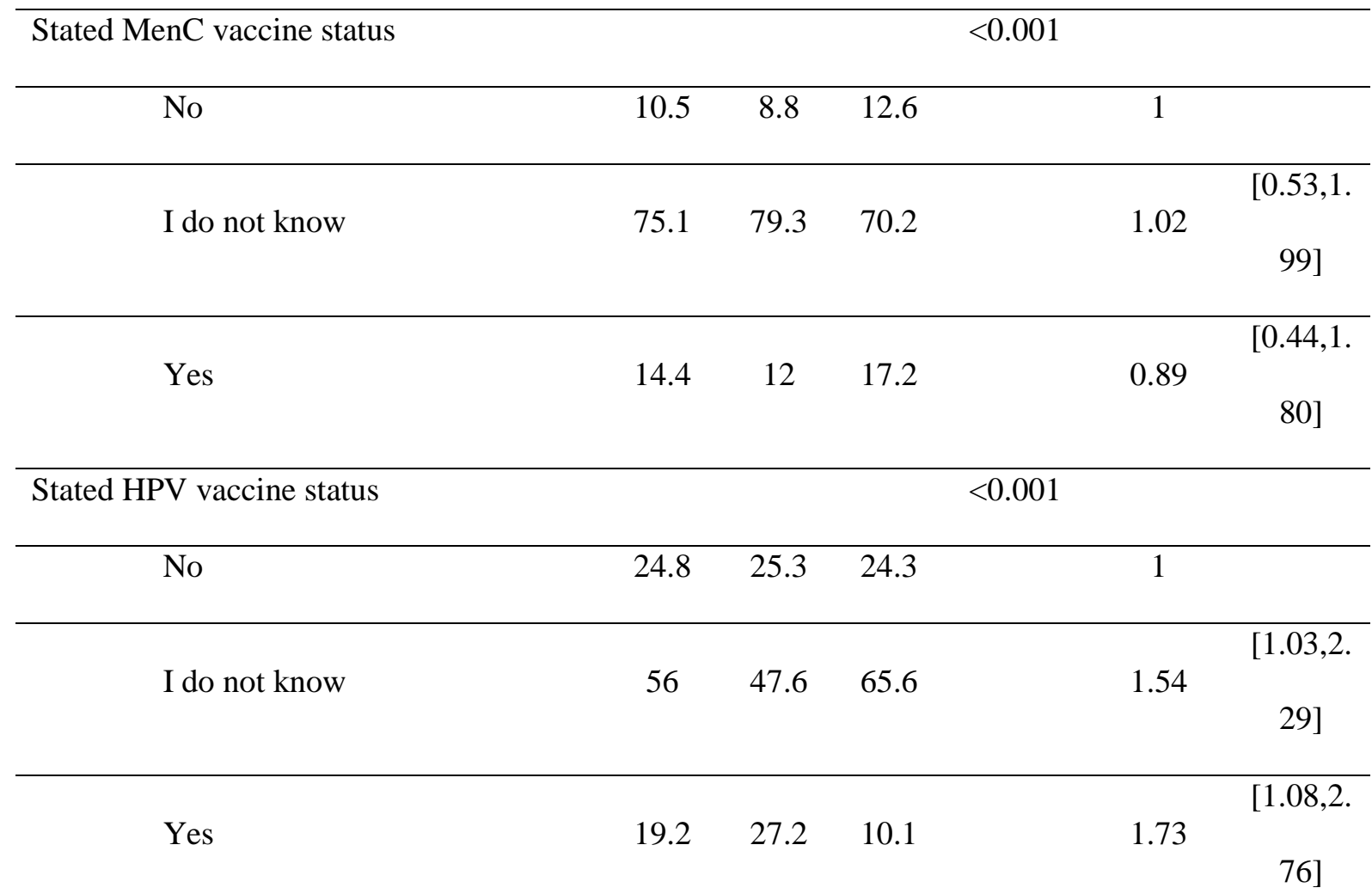

\begin{tabular}{|c|c|c|c|c|c|}
\hline Stated Hepatitis B vaccine status & & & & & \\
\hline No & 10.3 & 8.8 & 12.2 & 1 & \\
\hline I do not know & 64 & 66.6 & 60.9 & 1.45 & $\begin{array}{c}{[0.77,2 .} \\
74]\end{array}$ \\
\hline Yes & 25.7 & 24.6 & 27 & 1.62 & $\begin{array}{c}{[0.86,3 .} \\
05]\end{array}$ \\
\hline "It is useful to get vaccinated" & & & & & \\
\hline Disagree & 3.2 & 3.5 & 3 & 1 & \\
\hline
\end{tabular}


$\begin{array}{lll}91.9 & 90.4 \quad 93.8\end{array}$

3.66

$[1.75,7$.

65]

I do not know

$\begin{array}{lll}4.8 & 6.2 & 3.3\end{array}$

0.85

$[0.34,2$.

15]

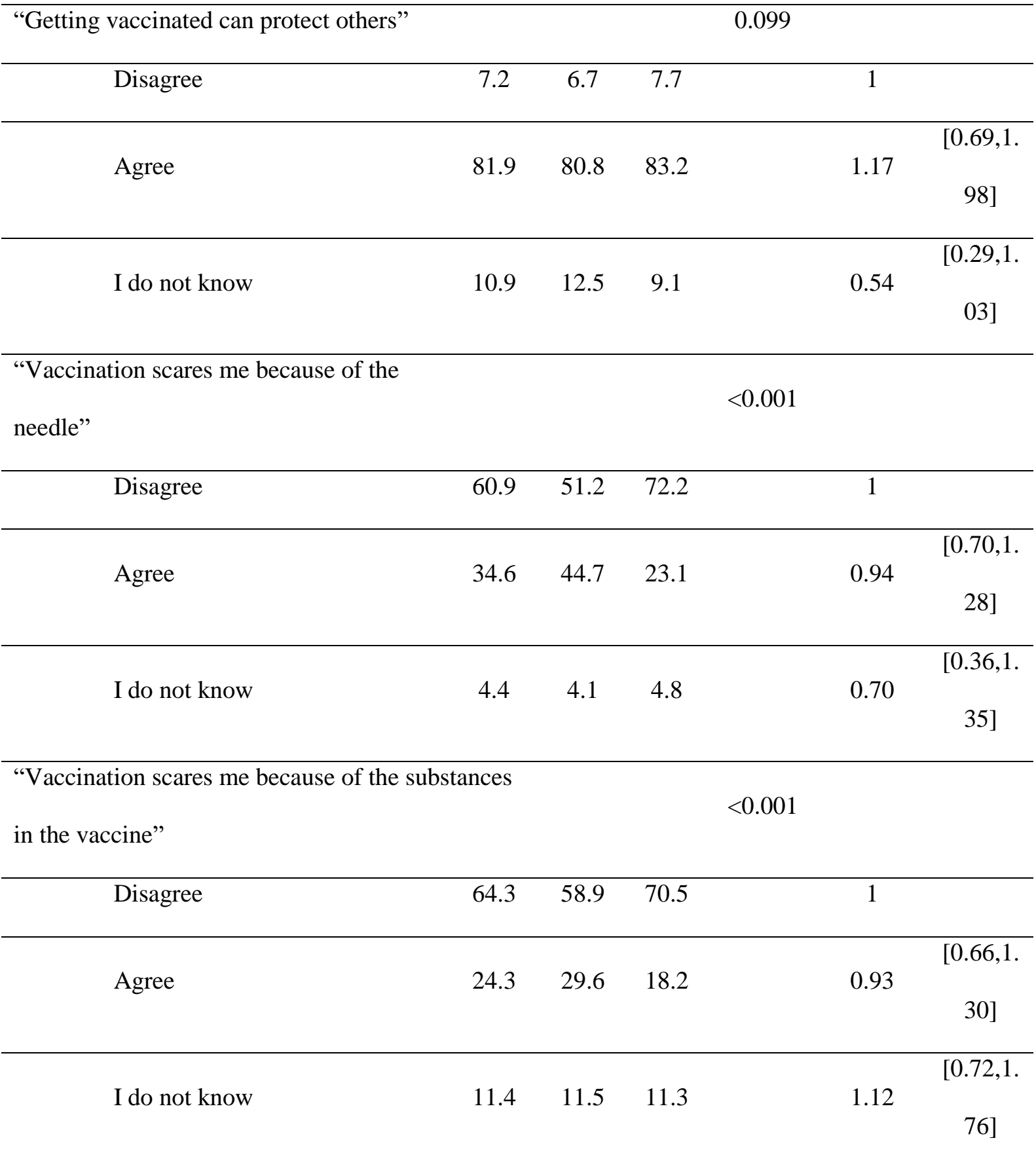

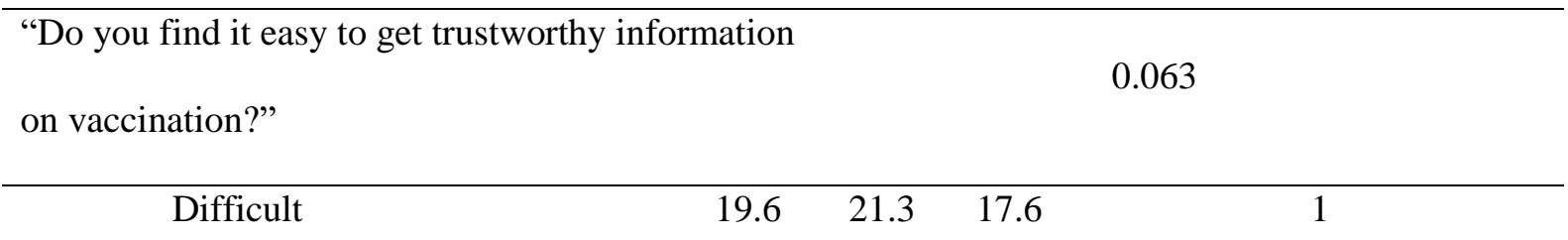


Notes: ${ }^{*}$ p-values obtained from Chi-square test comparing girls and boys on their individual characteristics. ** Odds ratios (OR) and confidence intervals $(95 \% \mathrm{CI})$ obtained from a full random effect multivariate logit model exploring the associations between vaccine acceptance and the listed individual characteristics. Tdap-IPV: Tetanus, Diphtheria, Pertussis, Polio; MMR: Measles, Mumps and Rubella; MenC: Meningococcal C; HPV: Human Papillomavirus. 
Table 3: Vaccination acceptance in the discrete choice experiment, overall and stratified by gender

Overall RE $(\mathrm{N}=1458) \quad$ Girls RE $(\mathrm{N}=780) \quad$ Boys $\mathrm{RE}(\mathrm{N}=678)$

\begin{tabular}{|c|c|c|c|c|c|c|c|c|c|c|c|}
\hline \multirow[b]{3}{*}{ Vaccine } & \multicolumn{4}{|c|}{ With } & \multicolumn{6}{|c|}{ With } & With \\
\hline & \multicolumn{2}{|c|}{ Main Effect } & \multicolumn{2}{|c|}{ interactions } & \multicolumn{2}{|c|}{ Main Effect } & \multicolumn{2}{|c|}{ interactions } & \multicolumn{2}{|c|}{ Main Effect } & interactions \\
\hline & $\mathrm{O}$ & $95 \%-$ & $\mathrm{O}$ & $95 \%-$ & $\mathrm{O}$ & 95\%- & $\mathrm{O}$ & $95 \%-$ & $\mathrm{O}$ & $95 \%-$ & 95\%- \\
\hline acceptance & $\mathrm{R}$ & CI & $\mathrm{R}$ & CI & $\mathrm{R}$ & CI & $\mathrm{R}$ & CI & $\mathrm{R}$ & CI & CI \\
\hline Attributes & & & & & & & & & & & \\
\hline
\end{tabular}

Respirator

y disease

$\begin{array}{llll}\text { (ref) } & 1 & 1 & 1\end{array}$

1. $[1.09, \quad 1 .[1.07, \quad 1 . \quad[1.11, \quad 1 . \quad[1.07, \quad 1 . \quad[0.88, \quad 1 . \quad[0.86$,

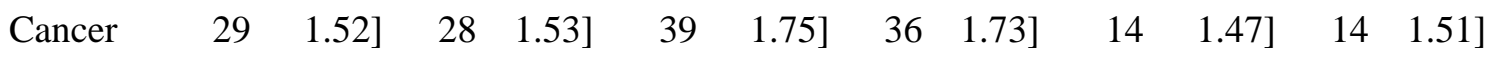

0. $[0.78, \quad 0 . \quad[0.82, \quad 1 . \quad[0.83, \quad 1 . \quad[0.88, \quad 0 . \quad[0.64, \quad 0 . \quad[0.63$,

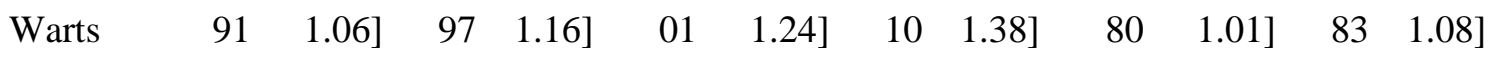

\section{Safety}

\begin{tabular}{|c|c|c|c|c|c|c|c|c|c|c|c|c|}
\hline No side & & & & & & & & & & & & \\
\hline effect (ref) & 1 & & & & 1 & & & & 1 & & & \\
\hline Scientific & 0. & {$[0.71$,} & 0 . & {$[0.75$,} & 0 . & {$[0.60$,} & 0 . & {$[0.63$,} & 0. & {$[0.73$,} & 1. & {$[0.75$,} \\
\hline surveillance & 86 & $1.04]$ & 94 & $1.18]$ & 78 & $1.00]$ & 85 & $1.16]$ & 97 & $1.30]$ & 05 & $1.48]$ \\
\hline \multicolumn{13}{|l|}{ Safety } \\
\hline other & 0. & {$[0.24$,} & 0. & {$[0.25$,} & 0 . & {$[0.20$,} & 0. & {$[0.20$,} & 0. & {$[0.26$, } & 0. & {$[0.27$,} \\
\hline countries & 30 & $0.36]$ & 31 & $0.38]$ & 25 & $0.33]$ & 27 & $0.36]$ & 35 & $0.47]$ & 37 & $0.51]$ \\
\hline Benefit/ris & 0. & {$[0.24$,} & 0 & {$[0.25$,} & 0. & {$[0.22$,} & 0 . & {$[0.23$,} & 0. & {$[0.22$,} & & {$[0.23$,} \\
\hline $\mathrm{k}$ & 30 & $0.36]$ & 31 & $0.39]$ & 29 & $0.38]$ & 31 & $0.41]$ & 30 & $0.41]$ & 31 & $0.43]$ \\
\hline
\end{tabular}




\section{Indirect}

\section{protection}

Protect

only you

(ref)

$1+1$

\begin{tabular}{lcccccccccccc}
\hline \multicolumn{1}{c}{ Protect } & 1. & {$[1.11$,} & 1. & {$[0.90$,} & 1. & {$[1.16$,} & 1. & {$[0.88$,} & 1. & {$[0.92$,} & 1. & {$[0.72$,} \\
others & 30 & $1.52]$ & 22 & $1.66]$ & 43 & $1.75]$ & 31 & $1.95]$ & 17 & $1.48]$ & 17 & $1.90]$ \\
\hline Eliminatio & 1. & {$[1.18$,} & 1. & {$[1.29$,} & 1. & {$[1.25$,} & 2. & {$[1.25$,} & 1. & {$[0.92$,} & 1. & {$[0.95$,} \\
$\mathrm{n}$ & 40 & $1.66]$ & 84 & $2.64]$ & 57 & $1.96]$ & 06 & $3.40]$ & 19 & $1.55]$ & 59 & $2.67]$ \\
\hline
\end{tabular}

\section{Coverage}

\begin{tabular}{|c|c|c|c|c|c|c|c|c|c|c|c|c|}
\hline Not & & & & & & & & & & & & \\
\hline enough (ref) & 1 & & & & 1 & & & & 1 & & & \\
\hline Already & 1. & {$[1.23$,} & 1. & {$[1.18$,} & 1. & {$[1.22$,} & 1. & {$[1.15$,} & 1. & {$[1.06$,} & & {$[0.93$,} \\
\hline one third & 48 & 1.78] & 63 & $2.25]$ & 56 & 2.00] & 76 & 2.69] & 41 & $1.88]$ & 53 & $2.54]$ \\
\hline Most & 1. & {$[1.64$,} & 2. & {$[1.50$,} & 2. & {$[1.62$,} & 1. & {$[1.25$,} & 1. & {$[1.44$,} & & {$[1.43$,} \\
\hline students & 98 & 2.38] & 02 & 2.72] & 09 & 2.68] & 87 & $2.78]$ & 91 & 2.52] & 25 & $3.53]$ \\
\hline \multicolumn{13}{|l|}{ Other } \\
\hline countries & 1. & {$[1.61$,} & 1. & {$[1.44$,} & 1. & {$[1.41$,} & 1. & {$[1.24$,} & 2. & {$[1.60$,} & 2. & {$[1.36$, } \\
\hline $80 \%$ & 94 & 2.35] & 97 & $2.68]$ & 81 & 2.33] & 86 & $2.80]$ & 15 & 2.89] & 21 & $3.61]$ \\
\hline
\end{tabular}

\section{Indirect}

Protection

*Coverage

Protect

others*Alrea

0. [0.56,

0. [0.42,

1. [0.47,

dy one third

94 1.57]

$82 \quad 1.60]$

$06 \quad 2.37]$ 
Protect

\begin{tabular}{|c|c|c|c|c|c|c|}
\hline others*Most & 1. & {$[0.66$} & & {$[0.76$} & 0. & {$[0.37$,} \\
\hline students & 05 & 1.67] & 42 & 2.63] & 75 & $1.53]$ \\
\hline \multicolumn{7}{|l|}{ Protect } \\
\hline \multicolumn{7}{|l|}{ others*Other } \\
\hline countries & 1. & {$[0.81$} & 1. & {$[0.71$} & 1. & {$[0.56$} \\
\hline $80 \%$ & 29 & 2.06] & 32 & $2.44]$ & 15 & 2.38] \\
\hline \multicolumn{7}{|l|}{ Eliminatio } \\
\hline $\mathrm{n}^{*}$ Already & 0. & {$[0.40$} & 0. & {$[0.37$,} & 0. & {$[0.26$} \\
\hline one third & 69 & $1.18]$ & 76 & $1.57]$ & 57 & 1.29] \\
\hline \multicolumn{7}{|l|}{ Eliminatio } \\
\hline n*Most & 0. & {$[0.49$} & 0. & {$[0.46$} & 0. & {$[0.36$} \\
\hline students & 79 & $1.26]$ & 86 & $1.64]$ & 72 & $1.46]$ \\
\hline \multicolumn{7}{|l|}{ Eliminatio } \\
\hline \multicolumn{7}{|l|}{$\mathrm{n} *$ Other } \\
\hline countries & 0. & {$[0.39$} & 0. & {$[0.30$} & 0. & {$[0.33$} \\
\hline $80 \%$ & 63 & $1.01]$ & 57 & 1.09] & 68 & $1.38]$ \\
\hline
\end{tabular}

RE: random effect specification. OR: Odds ratios. 95\%-CI: 95\% confidence interval 
Table 4: Probability of acceptance in scenarios with and without the additional attribute of sexual transmission

$$
\begin{array}{ccc}
\text { No mention of sexual } & \text { Mention of sexual } \\
\text { transmission } & \text { transmission } & \text { p-value }
\end{array}
$$

\begin{tabular}{lccccc}
\hline $\begin{array}{l}\text { Probability of } \\
\text { acceptance }\end{array}$ & $\%$ & $95 \%-C I$ & $\%$ & $95 \%-C I$ & \\
& 76.5 & {$[73.4,79.6]$} & 77.8 & {$[74.7,80.8]$} & 0.560 \\
\hline All & 77.7 & {$[73.6,81.8]$} & 77.0 & {$[72.9,81.2]$} & 0.814 \\
\hline Among girls & 74.9 & {$[70.1,79.7]$} & 79.0 & {$[0.74,0.83]$} & 0.257 \\
\hline Among boys & & & & \\
\end{tabular}




\section{Figures}

Reminder of the imaginary situation:

Your college offers a free vaccination by a doctor, for which you can sign up. Your parents are informed.

The vaccine protects very well against a common infection caused by a virus. The virus is transmitted through close contact. The general practitioners in your area support this vaccination.

Scenario 1

- The vaccine can protect against a cancer which could occur in 20 years from now.

- The infection is transmitted during sexual intercourse.

- The vaccine safety has been monitored for more than 10 years worldwide. No serious side effect has been scientifically confirmed.

- By getting vaccinated, you can avoid transmitting the infection to other persons.

- Already one third of students of your school have registered to get vaccinated.

Your decision:

I sign up myself $\bigcirc$ I do not sign up myself

Figure 1: Example choice task with the four main attributes and the added transmission attribute. 


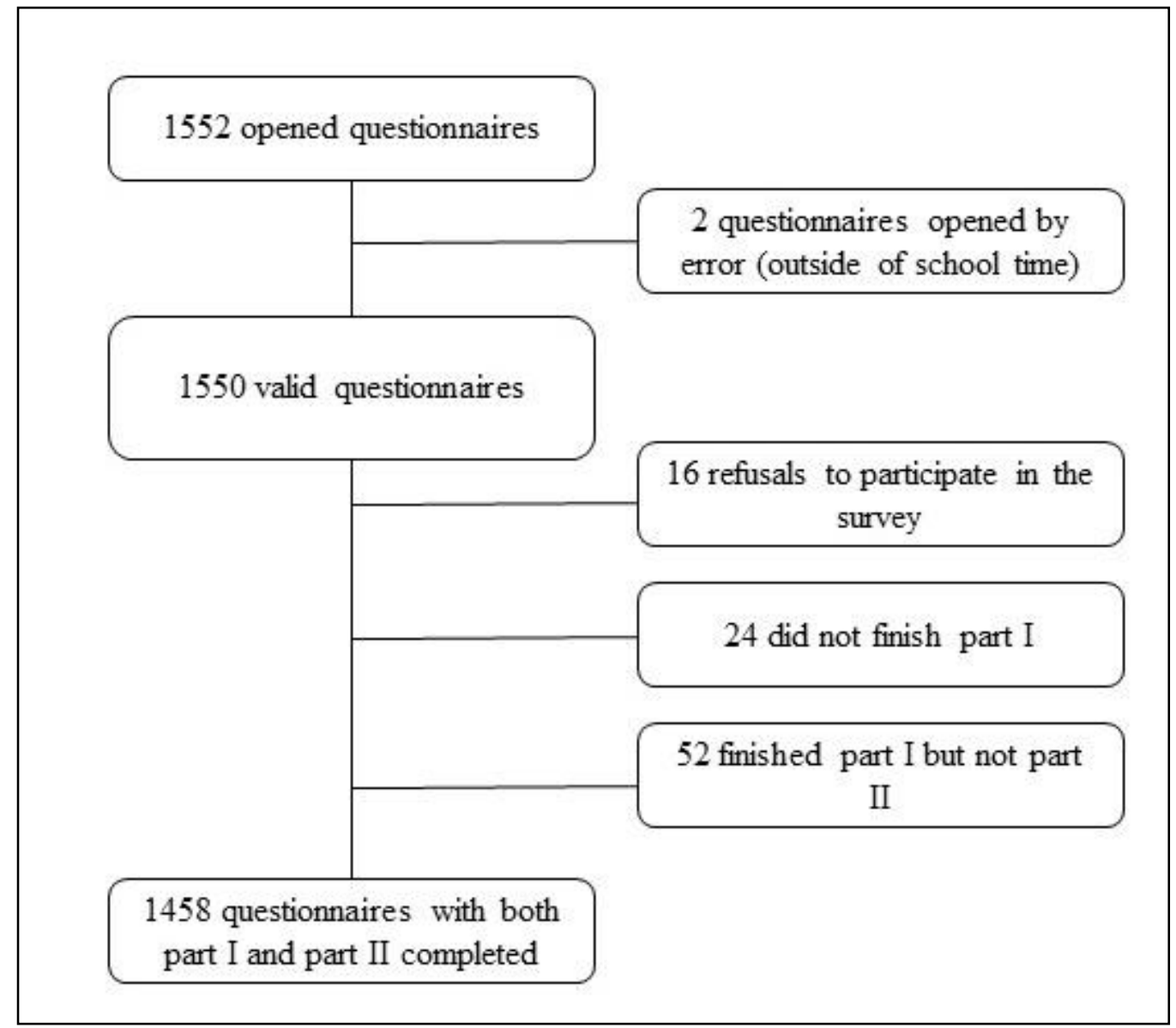

Figure 2: Flowchart of inclusions 


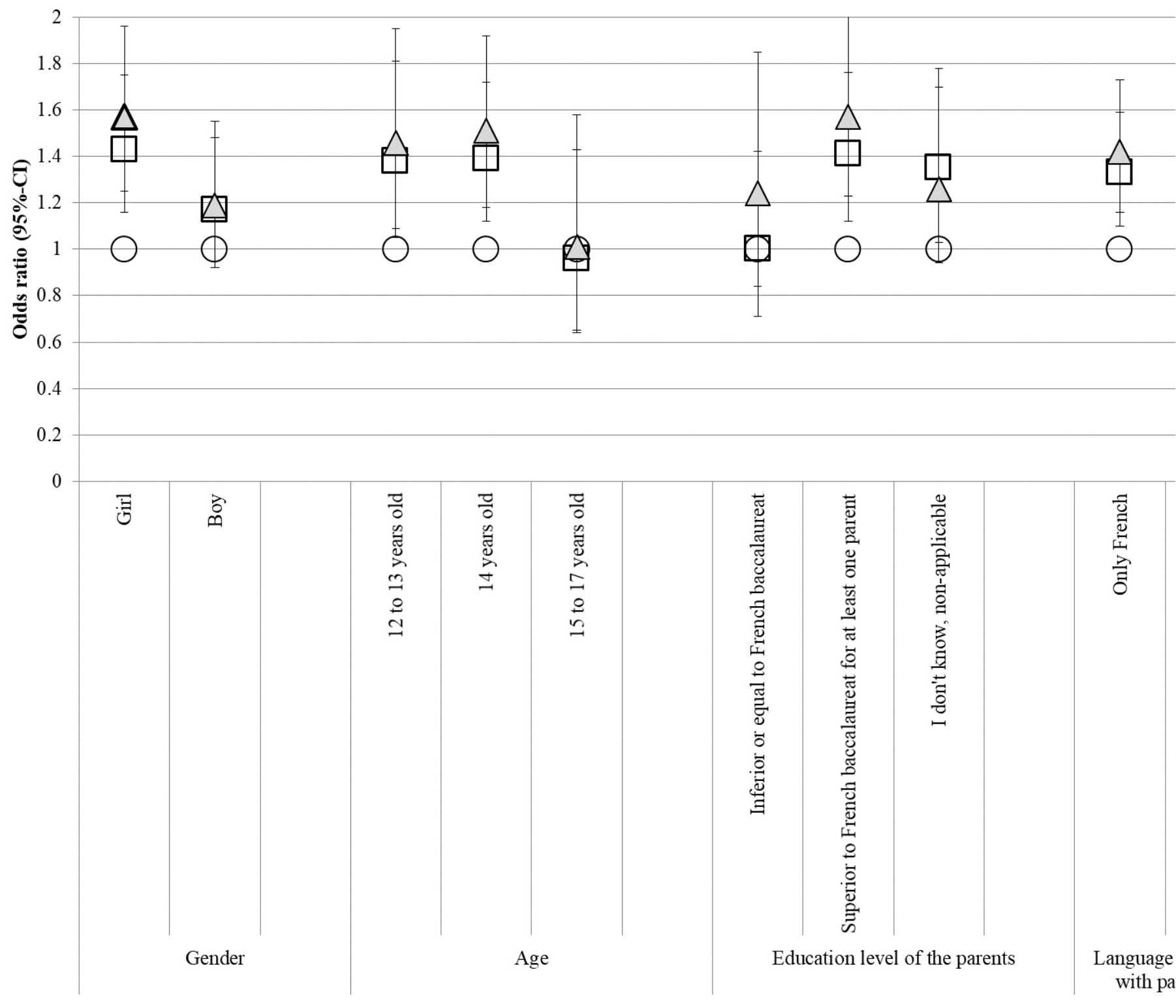

Figure 3: Vaccine acceptance for attribute levels regarding potential for indirect protection. Stratification on gender, age category, education level of the parents, and presence of a foreign language spoken with parents

Example interpretation: Compared to the level "Protects only you", the level "Protects others" has a significant effect on acceptance among girls, but not among boys. 


\section{Average Marginal Effects with 95\% CIs}

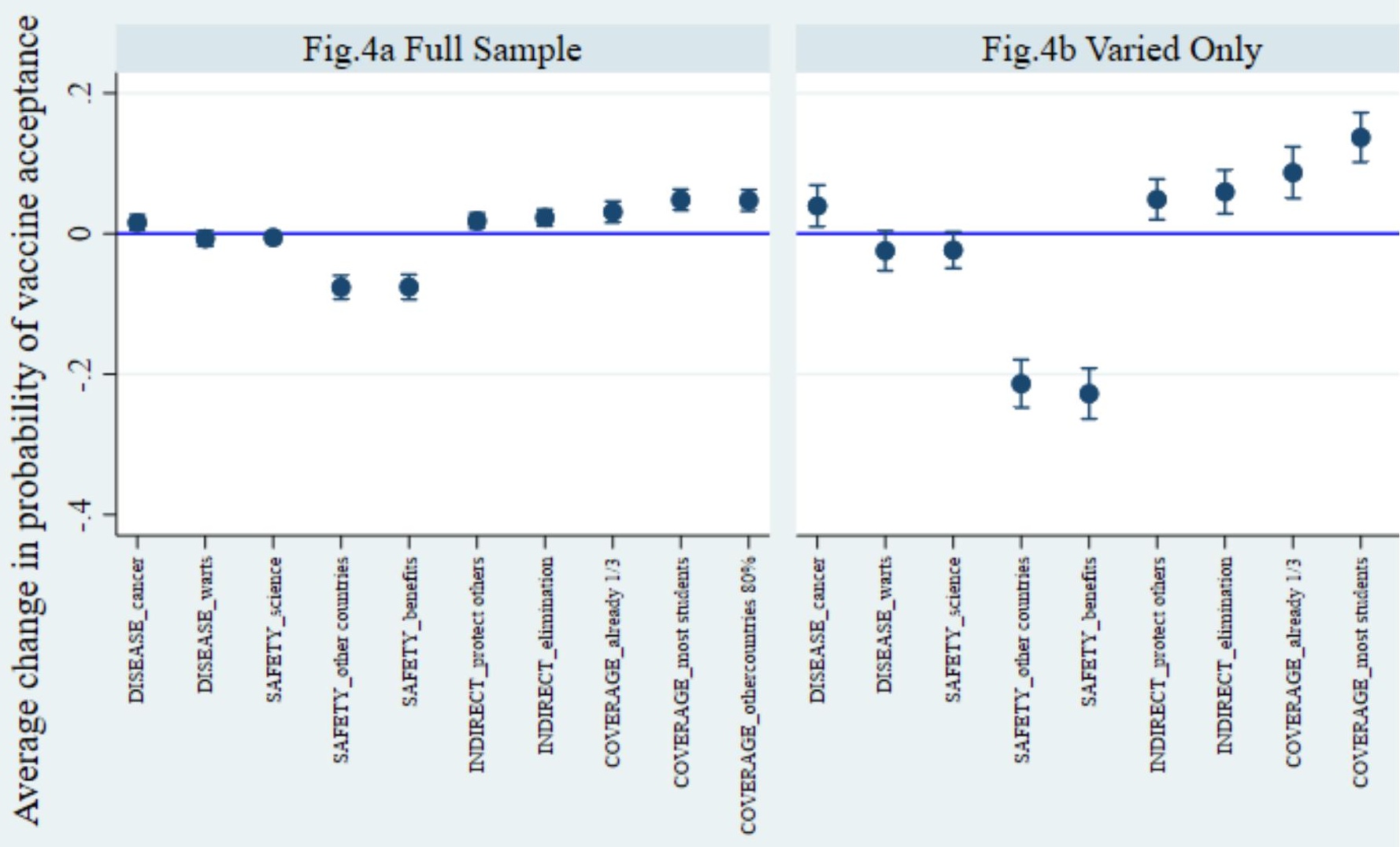

Attributes and levels

Figure 4: Average marginal effects of the attribute levels on the probability of vaccine acceptance. 4a: average marginal effects on the full sample $(n=1458)$. $4 \mathrm{~b}$ : average marginal effects on the subsample of those who varied in their decision at least once during the experiment $(n=711)$ 


\section{Supplementary Files}

Supplementary File A - Brief description of middle schools' characteristics

\begin{tabular}{|l|l|l|l|}
\hline & Public / Private & REP* & Urban / Rural \\
\hline School 1 & Public & Yes & Urban \\
\hline School 2 & Private & No & Urban \\
\hline School 3 & Public & No & Rural \\
\hline School 4 & Public & No & Rural \\
\hline School 5 & Public & No & Urban \\
\hline
\end{tabular}

*REP or "Réseaux d'éducation prioritaires" means schools located in deprived areas can beneficiate from a specific educational program aiming at reducing social and territorial inequalities. 
Supplementary File B - Information given before the choice tasks. (authors' translation)

Complete questionnaire in French available upon request.

Introduction following the questionnaire (1/5)

In this second part of the questionnaire, we ask you to imagine the following situation:

In your school, you can get vaccinated in a fortnight during an individual consultation with a general practitioner, free of charge. The school nurse will give you information to help you make a decision.

If you want to get vaccinated, you must register for an appointment. Your parents have been informed, and their agreement will be collected separately.

We are going to present you with 10 scenarios that differ in the information given by the nurse. For each scenario, we ask you to decide as you would in real life.

Introduction: Reminder of how vaccines work (2/5)

Our bodies are constantly exposed to various microbes. An infection means that our body is in contact with a germ, such as a virus, which can cause illness.

The body defends itself by making antibodies, substances that recognise and eliminate the microbe. Sometimes the body is not strong enough, and you get sick, or the microbe can stay in your body and cause illness long afterwards.

Vaccination allows the body to produce antibodies before you come into contact with the germ. The body is then ready to defend itself when it comes into contact with the germ.

If our body is infected with a germ, we may pass it on to others around us. Some vaccines, but not all, prevent you from spreading the infection to others. If many people are vaccinated, the germ can no longer infect anyone, and the disease disappears from the population.

Introduction: General description of the proposed vaccination in this imaginary situation (these elements apply to all scenarios) (3/5) 
* The vaccination presented is imaginary, so the information does not necessarily correspond to an existing vaccine.

* The vaccine protects against a common infection caused by a virus.

* The virus is transmitted by close contact. Anyone can be infected.

* The virus can also eliminate itself from the body without causing disease but vaccination is the only effective means of protection.

* The vaccine has good effectiveness; it protects against $90 \%$ of infections. The protection provided by the vaccine persists into adulthood.

* Like other vaccines, this vaccine may cause temporary effects: pain and redness at the site of the sting, fever, headache, or rare allergic reactions.

* The vaccine has been used in France and many other countries for 10 years or longer.

Introduction: Variable information (4/5)

The 10 scenarios vary according to the following information.

- The disease (consequences of the infection) against which the vaccine protects is either:

* An illness with a high fever and difficulty breathing, which can occur at any time and sometimes requires hospital treatment to prevent death.

* A cancer that may occur 20 years after infection. This cancer requires heavy treatment for several months, and 1 out of 3 patients dies from it.

* Condylomas (warts on intimate parts), which can occur at any time. These warts are not dangerous in themselves but can be very annoying. The treatment lasts several months, and warts come back easily.

- The possibility of serious side effects from the vaccine.

- To what extent getting vaccinated also protects other people.

- How many young people have signed up for the vaccine or are being vaccinated elsewhere.

Please note: some of the information comes from other European or English-speaking countries. 
Introduction: Instructions (5/5)

In each scenario, you will need to decide whether to register for the immunisation session.

The decision for each scenario will be:

I sign up

I do not sign up

You will then be asked how certain you are of your decision.

* Each scenario is different. Try to make your choice independently of the decisions made in the other scenarios.

* When making your choices, try to take into account all the information presented in the scenarios.

* There are no right or wrong answers. Only your opinion counts.

* You are encouraged to decide without taking into account the opinion that your parents or others may have.

Are you ready? 


\section{Supplementary File C -Modifications made on the attributes and levels}

Characteristics of adolescents testing the preliminary questionnaire via think-aloud

Girl, age 14

Boy, age 13

Girl, age 13

Boy, age 16

Boy, age 10.5

Modifications made on the attributes and levels:

- We removed an attribute on "vaccine effectiveness/controversy" which had two levels because it was judged too complex and not adapted for adolescents. The two levels were "In countries which have been using this vaccine for a while, one sees that the vaccine is very effective against the disease" and "you can read on the internet that one does not know if the vaccine really protects against the disease. It is true, but we know the vaccine is effective against the infection causing the disease".

- We simplified the levels by putting more information in the section introducing the DCE. For example, we described the potential diseases in the introduction instead of detailing them in the levels.

- We replaced the Disease level "the vaccine can protect against a disease that leads to complications during pregnancy" by "the vaccine can protect against a disease that gives a high fever and leads to a hospitalisation". We preferred to compare the levels "cancer" and "genital warts" to a usual childhood disease compared to another potential consequence of HPV. Introducing the pregnancy complications was a bit too complicated and could have led participants to think this vaccine is only for females, which we tried to avoid.

- We modified the Safety level "le vaccin est sûr" ("the vaccine is safe") by "Le vaccin ne provoque pas d'effet secondaire grave" ("the vaccine does not provoke serious side effect") because the first version was not well understood by test participants (some thought it meant the vaccine was effective).

- We removed one level of the Safety attribute to reach four levels instead of the original five to simplify the DCE design.

- We modified the Safety level "In countries who vaccinate adolescents for a long time, the risk of developing a serious illness after getting the vaccine has not increased" by "In 
countries who vaccinate most adolescents, the risk of a serious side effect which could be due to the vaccine has not increased"

- We modified the "Indirect" level "By getting vaccinated, you can avoid contaminating other persons" by "By getting vaccinated, you can avoid transmitting the infection to other persons." because it was more appropriate wording for this age.

- We replaced the "Coverage" level "Few young people have gotten registered" by "Not enough young people have gotten registered" to insist on the negativity of the statement, which is often used in vaccine communication but goes against social conformism. 
Supplementary File D - Average percentage of vaccine acceptance for each scenario; from lowest to highest

\begin{tabular}{|c|c|c|c|c|c|c|c|c|}
\hline Scenario & Disease & Safety & Indirect Protection & Coverage & $\begin{array}{l}\text { Sexual } \\
\text { Transmission }\end{array}$ & $\begin{array}{l}\% \quad \text { Theoretical } \\
\text { vaccine } \\
\text { acceptance }\end{array}$ & Number of & Total \\
\hline 13 & Febrile Illness & Safety other countries & Individual protection only & Not enough & & 64.0 & 224 & 350 \\
\hline 27 & Genital Warts & Safety other countries & Protects others & Not enough & & 68.1 & 278 & 408 \\
\hline 31 & Cancer in 20 years & Safety other countries & Individual protection only & Not enough & & 68.4 & 327 & 478 \\
\hline 5 & Febrile Illness & Benefit/risk & Protects others & Not enough & & 70.3 & 156 & 222 \\
\hline 38 & Genital Warts & Benefit/risk & Protects others & Already one third & & 72.1 & 344 & 477 \\
\hline 7 & Cancer in 20 years & Safety other countries & Individual protection only & Already one third & & 75.7 & 168 & 222 \\
\hline 28 & Genital Warts & Benefit/risk & Elimination & Other countries $80 \%$ & & 75.7 & 309 & 408 \\
\hline 11 & Cancer in 20 years & Benefit/risk & Individual protection only & Other countries $80 \%$ & & 76.3 & 267 & 350 \\
\hline 36 & Febrile Illness & Benefit/risk & Protects others & Other countries $80 \%$ & & 76.9 & 367 & 477 \\
\hline 18 & Febrile Illness & Safety other countries & Individual protection only & Most students & & 77.1 & 270 & 350 \\
\hline 34 & Cancer in 20 years & Benefit/risk & Protects others & Most students & & 77.4 & 369 & 477 \\
\hline 25 & Cancer in 20 years & Benefit/risk & Individual protection only & Already one third & & 77.5 & 316 & 408 \\
\hline 37 & Genital Warts & No side effect & Individual protection only & Not enough & & 79.3 & 378 & 477 \\
\hline 30 & Febrile Illness & No side effect & Individual protection only & Already one third & Yes & 80.2 & 327 & 408 \\
\hline 4 & Febrile Illness & Safety other countries & Elimination & Already one third & & 80.2 & 178 & 222 \\
\hline
\end{tabular}




\begin{tabular}{|c|c|c|c|c|c|c|c|c|}
\hline 22 & Cancer in 20 years $\mid$ & Benefit/risk & Elimination & Most students & & 80.4 & 328 & 408 \\
\hline 24 & Febrile Illness & No side effect & Individual protection only & Already one third & & 80.9 & 330 & 408 \\
\hline 15 & Genital Warts & Scientific surveillance & Individual protection only & Not enough & & 81.1 & 284 & 350 \\
\hline 16 & Genital Warts & Safety other countries & Elimination & Most students & & 81.1 & 284 & 350 \\
\hline 19 & Cancer in 20 years & Safety other countries & Protects others & Other countries $80 \%$ & & 81.4 & 285 & 350 \\
\hline 2 & Cancer in 20 years & Safety other countries & Protects others & Most students & & 81.5 & 181 & 222 \\
\hline 21 & Febrile Illness & Scientific surveillance & Protects others & Not enough & & 81.6 & 333 & 408 \\
\hline 29 & Genital Warts & Scientific surveillance & Elimination & Already one third & & 81.6 & 333 & 408 \\
\hline 9 & Genital Warts & No side effect & Elimination & Not enough & & 82.0 & 182 & 222 \\
\hline 20 & Genital Warts & Scientific surveillance & Individual protection only & Not enough & Yes & 82.3 & 288 & 350 \\
\hline 35 & Genital Warts & Scientific surveillance & Elimination & Other countries $80 \%$ & & 83.2 & 397 & 477 \\
\hline 32 & Cancer in 20 years & Scientific surveillance & Individual protection only & Most students & & 83.7 & 400 & 478 \\
\hline 39 & Febrile Illness & No side effect & Elimination & Not enough & & 84.1 & 402 & 478 \\
\hline 8 & Cancer in 20 years & Benefit/risk & Protects others & Other countries $80 \%$ & & 84.2 & 187 & 222 \\
\hline 40 & Genital Warts & Scientific surveillance & Elimination & Other countries $80 \%$ & Yes & 84.5 & 404 & 478 \\
\hline 33 & Genital Warts & No side effect & Elimination & Most students & & 84.7 & 405 & 478 \\
\hline 26 & Genital Warts & Scientific surveillance & Individual protection only & Other countries $80 \%$ & & 85.1 & 347 & 408 \\
\hline 1 & Genital Warts & No side effect & Individual protection only & Other countries $80 \%$ & & 85.1 & 189 & 222 \\
\hline 23 & Febrile Illness & Scientific surveillance & Elimination & Most students & & 85.5 & 349 & 408 \\
\hline 3 & Febrile Illness & Scientific surveillance & Elimination & Already one third & & 86.0 & 191 & 222 \\
\hline 6 & Cancer in 20 years & Scientific surveillance & Protects others & Already one third & & 86.0 & 191 & 222 \\
\hline
\end{tabular}




\begin{tabular}{|l|l|l|l|l|l|l|l|l|}
\hline 14 & Febrile Illness & No side effect & Elimination & Other countries $80 \%$ & & 86.9 & 304 \\
\hline 10 & Cancer in 20 years & Scientific surveillance & Protects others & Already one third & Yes & 86.9 & 193 \\
\hline 17 & Cancer in 20 years & No side effect & Protects others & Already one third & & 222 \\
\hline 12 & Febrile Illness & No side effect & Protects others & Most students & & 87.1 & 87.7 & 305 \\
\hline Total & & & & & 350 & 11677 & 14575 \\
\hline
\end{tabular}

The 40 scenarios were divided into four sets of 10 scenarios. Each respondent thus completed 10 scenarios, including one with the additional attribute (sexual transmission). 
Supplementary File E - Response Time by Uniform/varied decision

\begin{tabular}{lllllll} 
Response Time & Varied & & Uniform & \multicolumn{3}{c}{ Total } \\
\hline & $\%$ & Count & $\%$ & Count & $\%$ & Count \\
\hline More than 10 minutes & 74.4 & 529 & 71.62 & 535 & 72.98 & 1064 \\
\hline Less than 10 minutes & 22.93 & 163 & 25.84 & 193 & 24.42 & 356 \\
\hline Missing & 2.67 & 19 & 2.54 & 19 & 2.61 & 38 \\
\hline Total & 100 & 711 & 100 & 747 & 100 & 1458
\end{tabular}

Chi-square test: p-value: 0.433 
Supplementary File F - Results of random intercept logit models of vaccination acceptance including interactions between attributes and individual characteristics

Coefficient $\quad 95 \% \mathrm{CI}$

\begin{tabular}{|c|c|c|}
\hline Vaccine acceptance & & \\
\hline Attributes & & \\
\hline Disease & & \\
\hline Febrile illness (ref) & & \\
\hline Cancer & -1.21 & {$[-2.33,-0.09]$} \\
\hline Warts & 0.02 & {$[-0.99,1.03]$} \\
\hline Safety & & \\
\hline No side effect (ref) & & \\
\hline Science & 0.23 & {$[-0.90,1.35]$} \\
\hline Safety other countries & -0.64 & {$[-1.84,0.55]$} \\
\hline Benefits & 0.94 & {$[-0.28,2.17]$} \\
\hline Indirect Protection & & \\
\hline Protect only you (ref) & & \\
\hline Protect others & -0.31 & {$[-0.91,0.30]$} \\
\hline Elimination & 0.11 & {$[-0.46,0.68]$} \\
\hline Coverage & & \\
\hline Not enough (ref) & & \\
\hline Already one third & 0.13 & {$[-0.71,0.97]$} \\
\hline Most students & 0.14 & {$[-0.68,0.96]$} \\
\hline
\end{tabular}




\begin{tabular}{|c|c|c|}
\hline Attributes $*$ Individual characteristics & & \\
\hline Disease\# "It is useful to get vaccinated" & & \\
\hline Cancer\#Agree & 0.83 & {$[0.06,1.61]$} \\
\hline Safety\#Age category & & \\
\hline Benefit/risk\#14 years old & 0.41 & {$[0.04,0.79]$} \\
\hline Benefit/risk\#15 to 17 years old & 0.65 & {$[0.13,1.18]$} \\
\hline Safety\#Middle school & & \\
\hline Benefit/risk\#School 4 & -0.89 & {$[-1.58,-0.20]$} \\
\hline Safety\#" Getting vaccinated can protect o & & \\
\hline Benefit/risk\#Agree & -0.72 & {$[-1.39,-0.04]$} \\
\hline Benefit/risk\#I don't know & -0.85 & {$[-1.67,-0.03]$} \\
\hline Safety\#Stated Tdap-IPV vaccine status & & \\
\hline Benefit/risk\# I don't know & $-1.58 *$ & {$[-2.69,-0.46]$} \\
\hline Benefit/risk\#Yes & -1.37 & {$[-2.43,-0.32]$} \\
\hline Safety\#Stated MenC vaccine status & & \\
\hline Science\# I don't know & 1.00 & {$[0.22,1.77]$} \\
\hline Indirect Protection\#" Getting vaccinated c & & \\
\hline Protects others\#Agree & 0.71 & {$[0.13,1.28]$} \\
\hline Protects others\#I don't know & 0.71 & {$[0.01,1.41]$} \\
\hline Indirect Protection\#Stated HPV vaccine st & & \\
\hline Elimination\#Yes & 0.60 & {$[0.11,1.08]$} \\
\hline
\end{tabular}


Coverage\#In favour of vaccination

\begin{tabular}{|c|c|c|}
\hline Most students\#Agree or strongly agree & $0.57 *$ & {$[0.20,0.95]$} \\
\hline Other countries $80 \% \#$ Agree or strongly agree & 0.48 & {$[0.10,0.87]$} \\
\hline \multicolumn{3}{|c|}{ Coverage\# "Vaccination scares me because of the substances in the vaccine" } \\
\hline Already one third\#I don't know & -0.65 & {$[-1.20,-0.10]$} \\
\hline Most students\#I don't know & $-0.72 *$ & {$[-1.25,-0.19]$} \\
\hline
\end{tabular}

Note: variables were included in the final model if they interacted with one or more attributes at a p-value $<0.10$. Only variables with interaction at p-value $<0.05$ are showcased in this table $(*$ : p-value $<0.01)$. 
Supplementary File G - Vaccination acceptance in the "Overall sample" and the "Varied decision only" subsample

\begin{tabular}{|c|c|c|c|c|c|c|c|}
\hline \multirow[b]{3}{*}{ Vaccine acceptance } & \multicolumn{3}{|c|}{ Overall RE (N=1458) } & \multicolumn{4}{|c|}{ Varied decision only RE (n=711) } \\
\hline & \multicolumn{2}{|c|}{ Main Effect } & Interactions & \multicolumn{2}{|c|}{ Main Effects } & \multicolumn{2}{|c|}{ Interactions } \\
\hline & OR & $95 \%-\mathrm{CI}$ & $\begin{array}{ll}\text { OR } & 95 \%-\mathrm{CI}\end{array}$ & OR & $95 \%-\mathrm{CI}$ & OR & $95 \%-\mathrm{CI}$ \\
\hline Respiratory disease (reference) & 1 & & 1 & 1 & & 1 & \\
\hline Cancer & 1.29 & {$[1.09,1.52]$} & $1.30 \quad[1.09,1.54]$ & 1.25 & {$[1.06,1.48]$} & 1.27 & {$[1.07,1.51]$} \\
\hline \multicolumn{8}{|l|}{ Safety } \\
\hline No side effect (reference) & 1 & & 1 & 1 & & 1 & \\
\hline Scientific surveillance & 0.86 & {$[0.71,1.04]$} & $\begin{array}{ll}0.88 & {[0.72,1.07]}\end{array}$ & 0.84 & {$[0.70,1.02]$} & 0.85 & {$[0.70,1.03]$} \\
\hline Safety other countries & 0.30 & {$[0.24,0.36]$} & $\begin{array}{ll}0.30 & {[0.24,0.36]}\end{array}$ & 0.31 & {$[0.25,0.37]$} & 0.30 & {$[0.25,0.37]$} \\
\hline Protect others & 1.30 & {$[1.11,1.52]$} & $\begin{array}{ll}1.27 \quad[1.09,1.49]\end{array}$ & 1.30 & {$[1.11,1.51]$} & 1.28 & {$[1.09,1.49]$} \\
\hline Elimination & 1.40 & {$[1.18,1.67]$} & $\begin{array}{ll}1.40 \quad[1.18,1.66] \\
\end{array}$ & 1.38 & {$[1.16,1.63]$} & 1.38 & {$[1.16,1.64]$} \\
\hline \multicolumn{8}{|l|}{ Coverage } \\
\hline Not enough (reference) & 1 & & 1 & 1 & & 1 & \\
\hline Already one third & 1.48 & {$[1.23,1.78]$} & {$[1.23,1.78]$} & 1.54 & {$[1.28,1.84]$} & 1.53 & {$[1.27,1.84]$} \\
\hline Most students & 1.98 & {$[1.64,2.38]$} & {$[1.63,2.37]$} & 2.04 & {$[1.70,2.45]$} & 2.02 & {$[1.68,2.44]$} \\
\hline
\end{tabular}




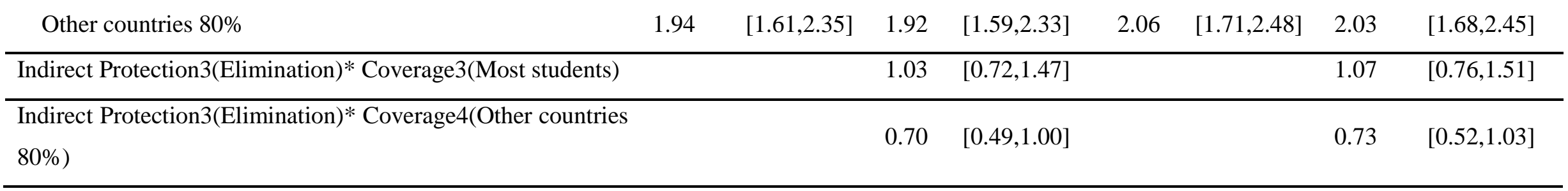

RE: random effect specification. OR: Odds-ratios. 95\%-CI: confidence interval at $95 \%$. 